\title{
Depressive Disorder Among Child And Adolescent Patients Attending Psychiatry OPD at Nepalgunj Medical College, Kohalpur
}

\author{
Adhikari J ${ }^{1}$, Belbase $\mathrm{M}^{2}$, Jalan $\mathrm{RK}^{3}$
}

\begin{abstract}
BACKGROUND: Depression is one of the common psychiatric problem among child and adolescents especially during the peri pubertal stage. It is found to be more common in females than males. Poor and unhealthy family atmosphere, family dispute, broken family, parents working abroad, physical abuse are few of the causes of childhood depression. Signs and symptoms of childhood depression may present with vague and atypical physical symptoms as compared to adults. Methods: This is a descriptive study done in patients attending psychiatry OPD of Nepalgunj Medical College, Kohalpur for the period of six months from July to December 2015. Results: Out of 245 patients, 142(57.9\%) patients were diagnosed as depressive disorder. Rest of the pediatric patients 103(42.1\%) attending the psychiatry OPD were of seizure disorder, bipolar disorder, conversion disorder, mental retardation, adjustment disorder etc. There were $88(62 \%)$ females and 54(38\%) male patients showing the majority of patients as females. The most common age group involved in the study population was $11-14$ years $116(81.7 \%)$ followed by $6-10$ years age group 23 (16.2\%) and up to 5 years $3(2.1 \%)$ respectively. Conclusion: Depression is quite common in pediatric population mostly during the peripubertal stage. It is seen most frequently in females.
\end{abstract}

Key words: Child and adolescent, depressive disorder, Nepalgunj Medical College

\section{INTRODUCTION}

Mental problem is very common but stigmatized medical and social problem worldwide. Mental disorders are not exclusive preserve of any special groups; they are truly universal. Mental and behavioral disorders are found in people of all regions, countries and all societies ${ }^{1}$.

Mental problem is equally common in children and adolescents. Child has been divided into two phases: preschool child (3-6 years), school age child (6-12 years). Similarly adolescence is divided into early (10-13 years), middle (14-16 years) and late (17-20 years) ${ }^{2}$.

The overall prevalence of depressive disorder in United States among 3-17 year old children is $2.1 \%$. The male: female ratio is $1: 1$ during childhood and beginning in early adolescence rises to 1:1.5-3.0 in adulthood. Major depression may first appear at any age, but the likelihood of onset increases markedly with puberty ${ }^{3}$. Some study also shows poor and unhealthy family atmosphere causing more chance in adolescents to suffer from greater academic problems, depression, suicidal thoughts,

\footnotetext{
1. Dr. Jyoti Adhikari

2. Dr. Mohan Belbase

3. Dr. Rekha Jalan
}

Address for correspondence:

Dr. Jyoti Adhikari

Department of Pediatrics

Nepalgunj Medical College \& Teaching Hospital,

Kohalpur, Banke, Nepal

Email: adhikarijyoti@yahoo.com substance abuse and more sexual activity ${ }^{4}$. Signs and symptoms of childhood depression may present with vague and atypical physical symptoms as compared to adults.

The national prevalence study of United Kingdom found that almost one child in 10(9.5\%) aged 5-15 years had psychiatric disorders based on ICD-10 (International Classification of Disease, $10^{\text {th }}$ edition) classification system. Prevalence was higher in adolescents ( $11.2 \%$ at $11-15$ years) than in children (8.2\% at $5-15$ years), and in boys $(11.4 \%)$ than in girls $(7.6 \%)^{5}$. Worldwide, it has been estimated that about $10-20 \%$ of children and adolescents suffer from mental problems ${ }^{6}$.

In developing country like Nepal, child and adolescent psychiatric problems are often neglected as there is no child psychiatrist and very few numbers of psychiatrists available at western part of Nepal. Also there is lack of awareness regarding child mental health among medical practitioners and other health care workers. Studies regarding depressive disorder among child and adolescent patients is very few from the western part of Nepal.

This study aims to show the prevalence and sociodemographic profile of child and adolescent depressive disorder from Tertiary care center from Western region of Nepal.

\section{MATERIAL AND METHODS}

This is a descriptive study done in patients attending psychiatry OPD of Nepalgunj Medical College, Kohalpur for the period of six months from July to December 2015. All new pediatric patients who presented at Psychiatry OPD, those referred from Pediatric department and Emergency department were 
included in the study. Total 245 patients were included in the study. Patients were diagnosed using ICD-10 classification of mental and behavioral disorders, clinical description and diagnostic guidelines.

Patients who did not want to participate in the study were excluded from the study group. Patients who needed psychological and pediatric intervention were sent to the psychologist and the pediatric department of the same hospital. Laboratory investigations required were done from the hospital laboratory. All the variables were recorded and analyzed using SPSS (Statistical Package for Social Studies) software and tabulated the percentage.

\section{RESULTS}

Out of 245 patients, $142(57.9 \%)$ patients were diagnosed as depressive disorder. Rest of the pediatric patients 103(42.1\%) attending the psychiatry OPD were of seizure disorder, bipolar disorder, conversion disorder, mental retardation, adjustment disorder etc. There were $88(62 \%)$ females and $54(38 \%)$ male patients showing the majority of patients as females.

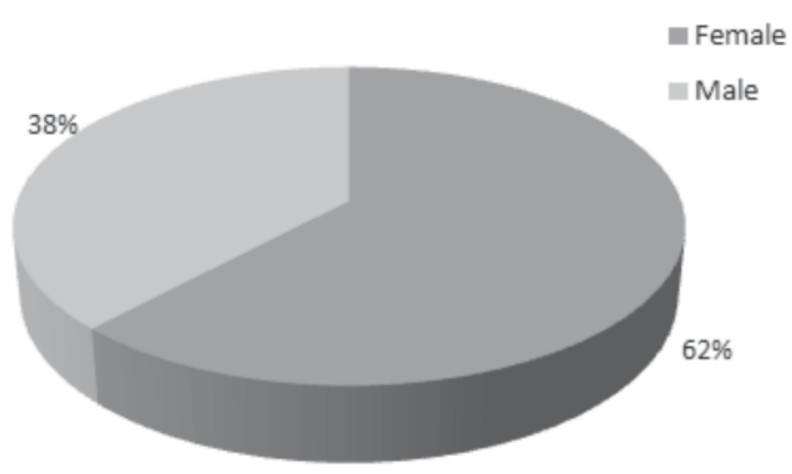

Figure 1: Sex distribution of patients

The most common age group involved in the study population was $11-14$ years $116(81.7 \%)$ followed by $6-10$ years age group $23(16.2 \%)$ and up to 5 years $3(2.1 \%)$ respectively.

\begin{tabular}{|c|c|c|}
\hline Age (years) & Frequency & Percentage (\%) \\
\hline Up to 5 & 3 & 2.1 \\
\hline $6-10$ & 23 & 16.2 \\
\hline $11-14$ & 116 & 81.7 \\
\hline Total & 142 & 100 \\
\hline
\end{tabular}

Table I: Showing age distribution of patients

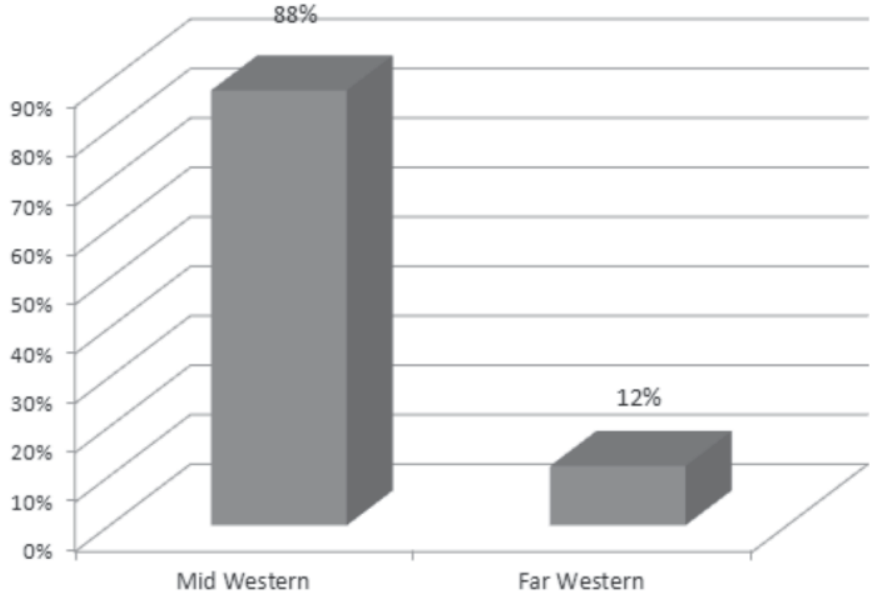

Figure 2: Figure showing geographic distribution of patients

As shown in Figure 2 maximum number of patients seeking psychiatric attention was from mid western region of Nepal $125(88 \%)$. Rests were from far western region $17(12 \%)$.

\begin{tabular}{|c|c|c|}
\hline Ethnicity & $\begin{array}{c}\text { Frequency } \\
\text { (n=142) }\end{array}$ & Percentage (\%) \\
\hline Brahmin & 38 & 26.8 \\
\hline Chhetri & 55 & 38.7 \\
\hline Tharu & 12 & 8.5 \\
\hline Gurung & 8 & 5.6 \\
\hline Others & 29 & 20.4 \\
\hline Total & 142 & 100 \\
\hline
\end{tabular}

Table II: Ethnicity distribution of patients

Chhetri were the most common ethnic groups seeking medical attention $55(38.7 \%)$ followed by Brahmin $38(26.8 \%)$, minority groups 29(20.4), Tharu 12(8.5\%) and Gurung 8(5.6\%) respectively.

\section{DISCUSSION}

Among the study population, females $(62 \%)$ were more common to have depressive disorder than males (38\%). The finding is similar to the another study done in tertiary hospital in Dharan, Nepal where majority of patients were female (53\%) than male $(47 \%)^{7}$. Also another study conducted at Dhulikhel Hospital showed female predominance $(71.4 \%)^{8}$.

The most common age group in the present study was 11-14 years. This was comparable with the study done in western part of Nepal where $33.33 \%$ of patients were in the age group of 10 14 years $^{9}$. In another study, the mean age of the patients was $14^{7}$. This surge in depressive cases in that age bracket could be due to pubertal hormonal changes ${ }^{3}$. Age distribution of this study shows that we had patients with younger groups as 
compared with other studies ${ }^{7,8}$. This was because the age of the study groups was limited to 14 completed years as most of the patients were referred from pediatric OPD.

Most of the patients seeking medical attention came from midwestern region of Nepal accounting for $125(88 \%)$ as compared to far-western region $17(12 \%)$. This is due to the mid-western location of this hospital and thus more patients from midwestern region can easily access medical help. Also, unawareness towards psychiatric problems to the people of far-western region land up to the traditional healers as compared to the medical facility.

Ethnic distribution was as per the distribution of national and regional population distribution given by the central bureau of statistics, government of Nepal in which the most common ethnicity is Chhetri ${ }^{10}$. Our study consisted of $38.7 \%$ of chhetri population.

In one study regarding mental health services for adolescents, it has been mentioned that mental health care should be integrated using cross-sectoral strategies into the communities in which adolescents live, the institutions they attend, the educational programs they receive, the media to which they are exposed and the organizations in which they participate ${ }^{11}$. Hospital based study, small sample size, unable to randomize were limitations of the study.

\section{CONCLUSION}

Depression is quite common in pediatric population mostly during the peripubertal stage. It is seen most frequently in females.

\section{ACKNOWLEDGEMENTS}

My sincere thanks to Lord Buddha Educational Academy, NGMCTH, Kohalpur administration, Principal's office and psychiatric department for their valuable contribution.

\section{REFERENCES}

1. Park K. Park's textbook of preventive and social medicine. $12^{\text {th }}$ ed. Jabalpur: M/s Banarasidas Bhanot; 2009. p. 734.

2. Paul VK, Bagga A. Ghai Essential Pediatrics. $8^{\text {th }}$ ed. Normal growth and its disorders: CBS publishers \& Distributers; 2013. p.9.

3. Kliegman RM, Stanton BF, St Geme JW, Schor NF. Nelson Textbook of Pediatrics. 20 $0^{\text {th }}$ ed: Behavioral and psychiatric disorders; Elsevier; 2016. p. 151-56.

4. Chhabbra GS, Sodhi MK. Impact of Fmily Conflict on the Psychosocial Behavior in Male Adoloscents. J. Nepal Pediatr. Sco. 2012;32(2):124.

5. Gelder MG, Andreasen NC, Lopezlbor JJ, Geddes JR. New Oxford Textbook of Psychiatry. $2^{\text {nd }}$ ed. United Kingdom; Oxford University Press; 2009. p. 1595,1606.

6. Baddick F, Carrel V, Jenkins R, Jane-Llopis E. Child and Adolescent Mental Health in Europe: Infrastructures, Policy and programmes. Luxembourg: Europian Communities; [cited 2016
18 ].

http://ec.europa.eu/health/ph_determinants/life_style/mental /docs/camhee_infrastructures.pdf

7. Shakya DR. Psychiatric Morbidity Profiles of Child and Adolescent Psychiatric Outpatients in a Tertiary Care Hospital. J. Nepal. Paediatr. Soc. 2010;30(2): p.79-84.

8. Risal A, Sharma PP. Psychiatric illness in the Pediatric Population Presenting to a Psychiatry Clinic in a Tertiary Care Centre. Kathmandu University Medical Journal. 2010;8(32): p. 375-81.

9. Belbase M, Adhikari J, Jalan RK, Khan TA, Kaul V et al. Sociodemographic Profile with Distributions of Child and Adolescent Neuropsychiatric Problems. JNGMC. 2012;10(2): p. 12-5.

10. Government of Nepal, National planning commission secretariat, central bureau of statistics. July 42011.

11. Fisher JRW, de Mellow MC. Using the World Health Organization's 4S - Framework to Strengthen National Strategies, Policies and Services to Address Mental Health Problems in Adolescents in Resource-constrained Settings. International Journal of Mental Health Systems. 2011 Sept 16 [Cited Dec 18 2016]; 5(23):[about 2 screens]. Available from: http://www.ijmhs.com/content/5/1/23. 